\title{
Date of Cardiac Diagnostic Procedure
}

National Cancer Institute

\section{Source}

National Cancer Institute. Date of Cardiac Diagnostic Procedure. NCI Thesaurus. Code C80415.

The date that a specific cardiac diagnostic procedure was performed. 